\title{
ABOUT SIGN LANGUAGE TRANSLATOR APPLICATION
}

DOI: $10.24234 /$ se.2021.3.1.267

\begin{abstract}
AUTHORS' DATA
Armine Navasardyan, PhD in Technical Science, Associate Professor

Chair of Informatics and its teaching methods

Khachatur Abovyan Armenian State Pedagogical University, Armenia

Contacts: navasardyanarmine06@aspu.am

Gohar Knkoyan, Laboratory assistant

Chair of Informatics and its teaching methods

Khachatur Abovyan Armenian State Pedagogical University, Armenia

Contacts: khnkoyangohar06@aspu.am
\end{abstract}

\begin{abstract}
The Sign language translator is a trilingual mobile app for translating speech into international sign language. The developed mobile application is designed for the people who have hearing problems and use sign language. It converts imported audio information into texts and simultaneously translates it into the international sign language.

The application works for Armenian, Russian and English languages. It has an admin module that allows you to add new words, edit or remove them. It has simple three-language operating interfaces. The application works on both Windows and Android operating systems. It does not require additional resources or investments. It can be useful for inclusive societies and education.
\end{abstract}

Key words: International sign language, sign language translator, sign language dictionary, online learning, multi-layered training, multi-criterion training.

\section{INTRODUCTION}

People with hearing problems are everywhere. Societies treat them well and want to ensure full involvement in the socio-economic and cultural spheres. However, it is not an easy process. In a situation where online learning has spread to many countries around the world due to the coronavirus, the problem has become more and more complicated for this segment of the society. We offer our solution to the problem. 
On October 2, 2010, Armenia adopted the UN Convention about the "Rights of People with Disabilities", according to it the state parties recognize educational right of people with disabilities.

We did a statistical survey for the period 2011-2020. As a result, it turned out that many hearingimpaired citizens are deprived of their right to education (the results of the statistics are given in Appendix A).

We tried to understand the causes and:

- we made our own test questionnaire to find out that the Armenian society is not ready for the integration process (Test questionnaire and results are presented in Appendix B).

- we investigated the disabled people problems and found out that they are not often ready for the integration process.

- we researched the Armenian market and detected that there are not enough technical means (Situation in the international market is shown in Appendix C).

\section{THE PURPOSE OF THE WORK}

Create a mobile app that will help people with hearing problems integrate into society, especially in the field of education.

We tried to understand how this problem is solved in the international market:

- We studied the international experience.

- We analysed the existing solutions.

- We found our competitors.

- We discovered their strengths and weaknesses.

Here are the results of analysis:

- We almost don't have competitors in the Armenian market.

- The demographic distribution in Armenia forces to have a trilingual system (Armenian, Russian and English).

- There are many foreign language apps on the international market (mostly in English).

- Our competitors are serious organizations.

\section{THE TASKS}

To achieve our goal, we set out the following tasks 
- To create a sign language translator with the Armenian interface. It must support Russian and English languages.

- To expand the application for Windows and Android operating systems /for PC and mobile/.

\section{THE APPLICATION DESCRIPTION}

The Sign language translator is a trilingual mobile application (app) for translating speech into international sign language (Adam, 2012; Woll \& Ladd, 2003). It can be installed on the mobile smartphones and its logo will be on the screen (Picture 1). After running the app, the user can see the general interface (Picture 2).

\section{Picture 1.}

Sign language translator app's logo.

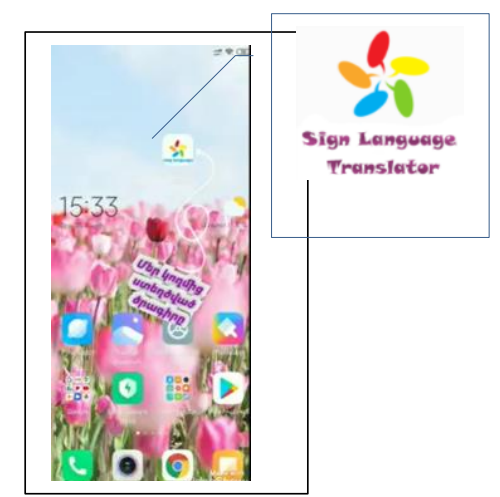

\section{Picture 2.}

Sing language translator app /User interface.

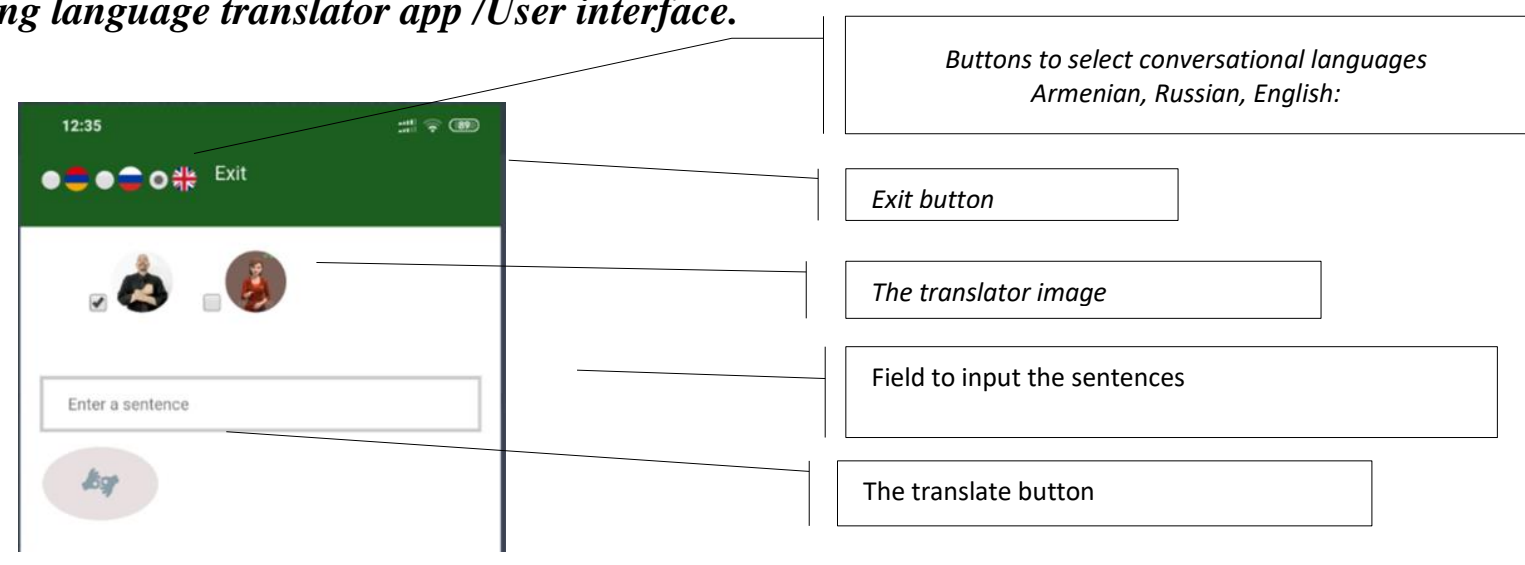

In this interface, first of all the user chooses a language by the country flags (Armenian is a default, but the user can select Russian or English languages as well). Secondly, the user must choose the translator image (male or female). The user must check a flag in front of the image. Only after that 
the user can input sentences or a word in the input field. When the user clicks on the translate button, the application translates the text into the sign language.

Besides typing, the user can speak, the app will type all the text into the sentence input field, and translate it to the sign language, too. Picture 3 shows inputting the sentence in the input field and the result for both cases (typing or speaking).

\section{Picture 3.}

\section{Sign language translator app's user interface (Input and Result data).}

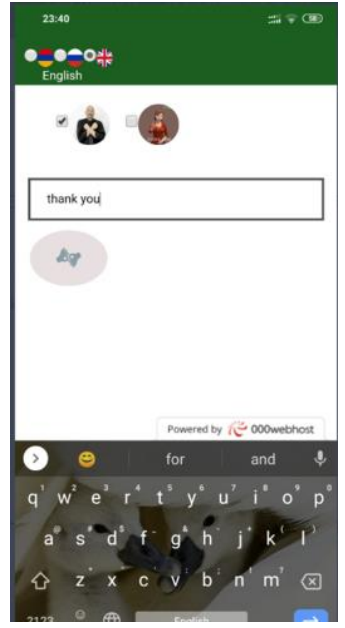

Input data

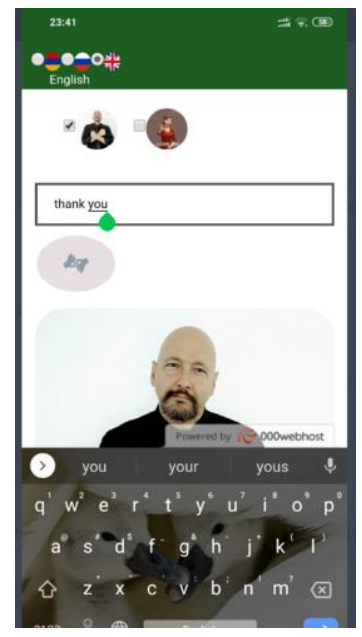

Result data

This application has an admin module. It is designed for inputting new data, as well as editing or removing them. The admin module consists of one super and several admins. The super admin supports all admins and gives them passwords for a login in the system. Every admin can see the data which was input by himself/herself and can edit or remove them. Super admin can see all admins and their data, and can change it all. He can remove even other admins.

The admin interface is the same as user's interface. Admin's general interface has an "Admin" button for login. Picture 4 shows admin's general interface and login interface. The admin interface, after logging in, takes the user to another interface for adding, editing or removing data. For data adding admin must click "+Adding” button. So, another interface opens on the mobile screen (Picture 5). The admin can input all data in Armenian, Russian, English and also short videos presenting input word. For saving all the data, admin must click on the "Save" button. If admin want to cancel the work, he/she must click on the "Cancel" button.

To see all the data, the admin should click on "General list" button. To edit a data, the admin should click on "Edit" button. The editing interface is similar to adding interface. In the editing interface the admin can change old data and save them.

To delete a data admin should click on "Delete" button. The app confirms query and deleting the record.

The admin can be any operator. But super admin must be a master of the field, who is responsible for the correct data. 


\section{Picture 4.}

Sign language translator Admin general interface and Admin login interface.
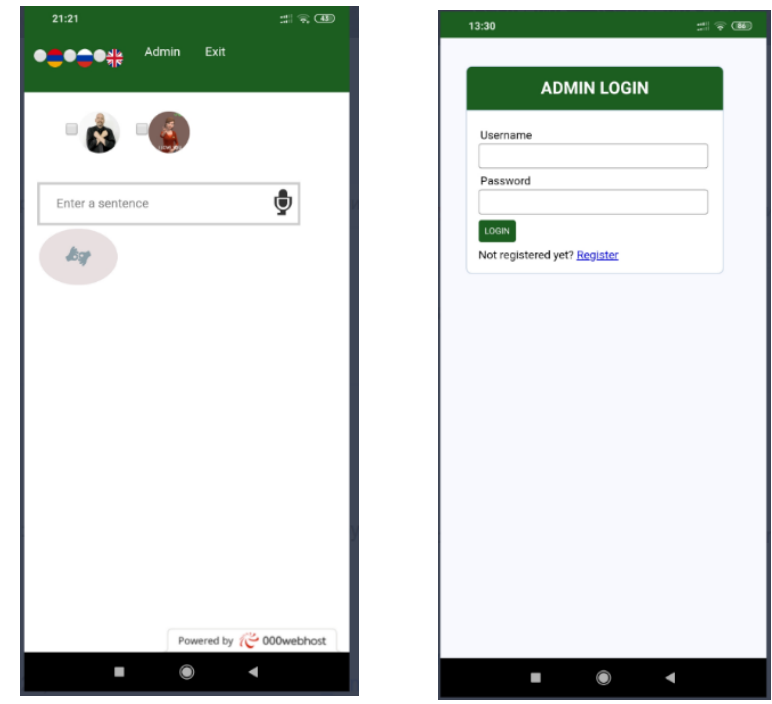

Picture 5.

Sign language translator Admin general interface and Admin login interface /data adding or editing interface/.

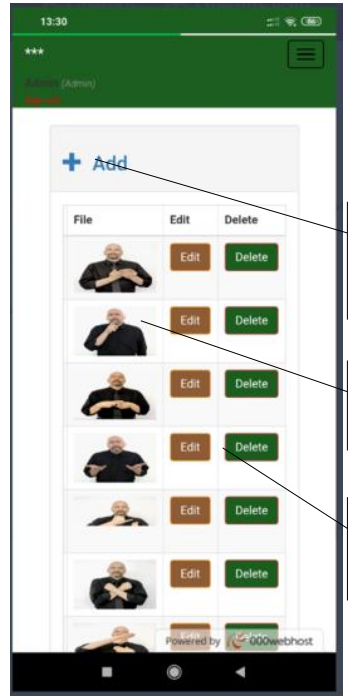

Sing language translate Admin interface

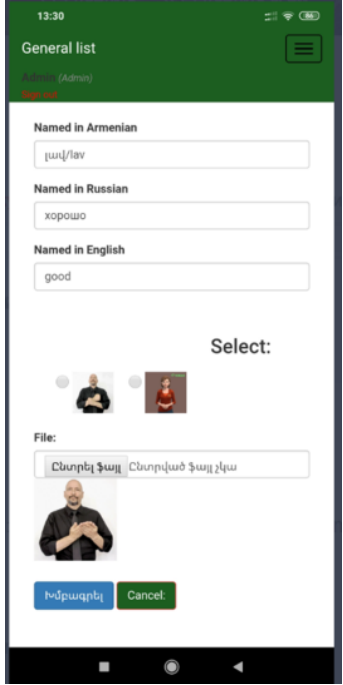

Sing language translate Admin interface /data adding or editing interface/

The application is designed on the HTML, CSS, JS PHP MySQL technologies (Alekseev, 2019; Gosudarev, 2019; Prokhorenok \& Dronov, 2015).

To interface design, we used HTML and CSS. To add a text to speech function on our application we used Javascript, we used the Web Speech API, which can be used to synthesis speech which is converting text to speech, and we can also use it to recognize speech to convert speech to text. We used the following interfaces/property: SpeechSynthesis, SpeechSynthesisUtterance and window.speechSynthesis. 
JavaScript SpeechSynthesis Interface is the main controller interface for the speech synthesis service which controls the synthesis or creation of speech using the text provided.

The SpeechSynthesisUtterance Interface is the interface in which we actually create the speech or utterance using the text provided, setting a language type, volume, pitch of the voice, rate of speech, etc.

The JavaScript window.speechSynthesis property of the Javascript window object is used to get the reference of the speech synthesis controller interface, on which we call the speaking method.

To data base we used MySQL server and for connection to Web browser we used PHP (see Appendix D).

\section{TESTING}

After the design work was completed, we tested it and conducted a survey again. We wanted to find out if there were any flaws in the project. Besides, we wanted to get new offers. We made tests consisting of 10 questions and got statistics again. It is presented in Appendix E.

\section{SUMMARY}

Hence, we have developed application that works on the Windows and Android operation systems. It has 2 modules: users and admin. In the developed application both modules have 3 language interfaces and can work with Armenian, Russian and English words data bases. All interfaces are very easy and comfortable to use. The app can translate a word, a sentence or speech into the sing language.

The app is open for adding new words, editing or removing words. So the app can be used to create a new language dictionary (German, Spanish, Chinese, Japanese, etc.).

The developed application increases the accessibility of a device for individuals with disabilities and can be useful for deaf and dumb people and all those who have hearing problems. It can be useful in education to train students or while performing daily activities. The application can be useful and play an important role in the process of building an inclusive society and increasing participation of deaf and dumb in social life.

\section{REFERENCES}

1. Adam, R. (2012). Language contact and borrowing. In R. Pfau, M. Steinbach, \& B. Woll (Eds.), Sign language: An international handbook (pp. 841-861). Berlin, Germany: De Gruyter Mouton. 
2. Woll, B., \& Ladd, P. (2003). Deaf communities. In M. Marschark and P. Spencer (Eds.), The handbook of Deaf studies, language, and education (pp. 151-163). Oxford, UK: Oxford University Press.

3. Alekseev, A. (2019). Introduction to Web design. Publishing house: Solon-press; ISBN: 9785-91359- 355-9 Pages 184

4. Gosudarev, I. (2019). Introduction to web development in JavaScript. Tutorial. Publishing House Lan Spb Series Books for universities. ISBN 9785811435395 Pages 144.

5. Prokhorenok, N., \& Dronov, V. (2015). HTML, JavaScript PHP MySQL, Ed. SPb: BHV-St. Petersburg 2015 978-5-9975-3130-6

6. UN. (2006). Convention on the rights of persons with disabilities. 
Appendix A

\section{People with hearing problems in Armenia}

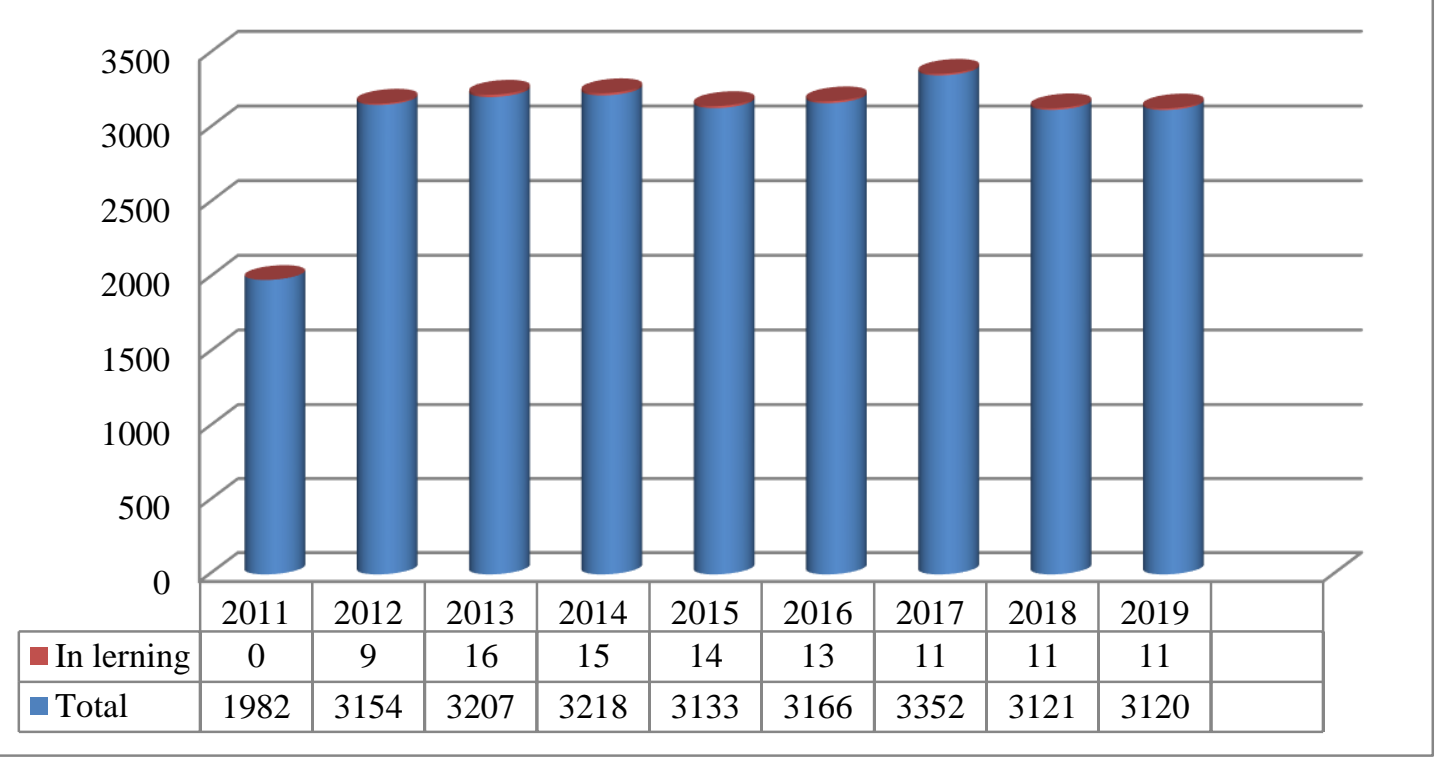


Test questions

Query 1
Is it right to abolish special
schools?
$\square \quad$ Yes $-3 \%$
$\square \quad$ No $-78 \%$
$\square \quad$ I don't know $-17 \%$
$\square \quad$ Other answer $-3 \%$

\section{Query 4}

It will be very difficult for your child?

\section{- Yes $-50 \%$ \\ - No $-47 \%$ \\ I I don't know - $1 \%$ \\ - Other answer $-2 \%$}

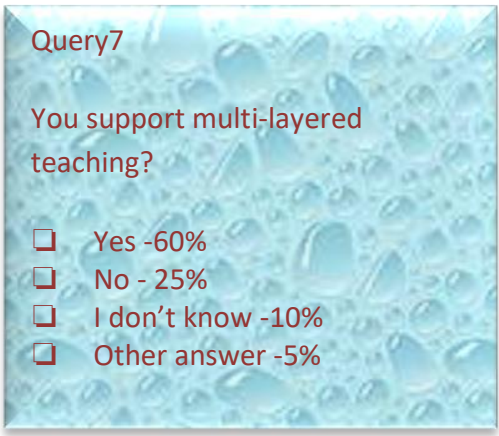

\section{Query 10}

Are you knowing what is a multilayered teaching?
- Yes $-75 \%$
- No $-25 \%$
I don't know $-0 \%$
- Other answer $-0 \%$

Query 2

Do You want to be a deaf and

dumb child in the classroom with your child?

D Yes $-8 \%$

D No- $73 \%$

- I don't know -3\%

- Other answer $-16 \%$

\section{Query 5}

It will be very difficult for that child?
$\square \quad$ Yes $-35 \%$
$\square \quad$ No $-55 \%$
$\square \quad$ I don't know $-5 \%$
$\square \quad$ Other answer $-5 \%$

Query 8

Will you want your child to attend a special school?

- Yes $-95 \%$

口 No- $0 \%$

- I don't know -3\%

- Other answer $-7 \%$

\section{Query 11}

Are you listen about sing language automatic translators?
- Yes $-80 \%$
- No - $15 \%$
- I don't know - $0 \%$
Other answer $-5 \%$

\section{Appendix B}

Query 3

Is it convenient to see a special pedagogue in the classroom?

- Yes $-5 \%$

- No - $75 \%$

- I don't know -13\%

$\square$ Other answer $-7 \%$

\section{Query 6}

Will have that child a problem communicating?

- Yes $-95 \%$

- $\mathrm{No}-0 \%$

I I don't know -3\%

Other answer $-2 \%$

Query 9

If your child has problems, you will prefer to keep them at home?

- Yes $-5 \%$

- No - $89 \%$

- I don't know - $1 \%$

$\square$ Other answer $-5 \%$

\section{Query 12}

Can computer/mobile translators help such people in the education?

- Yes $-92 \%$

No $-6 \%$

I I don't know -2\%

$\square \quad$ Other answer $-0 \%$ 


\section{Result diagram}

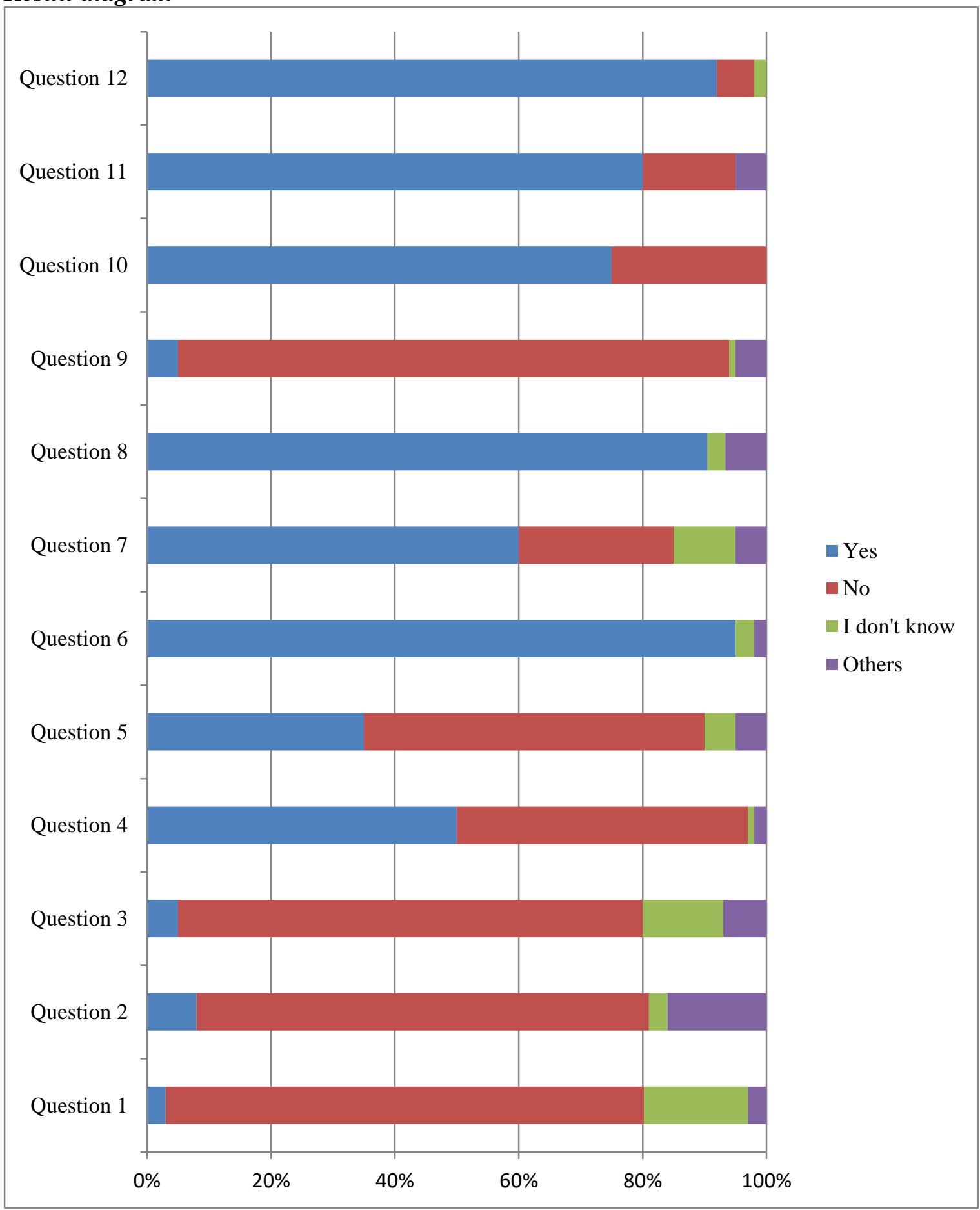


Table 1.

\section{Market players and their opportunities}

https://play.google.com/store/apps/details?id=ru.avroravent

ures.com.russiansinglanguage

Mind Rockets Inc

https://play.google.com/store/apps/details?id=com.mindroc

ketsinc.mimix

Daniel Mitchel

https://play.google.com/store/apps/details?id=com.signasl.s

ignasl

jpgironb

https://play.google.com/store/apps/details?id=com.jpgironb

assistiveguru

Software Studios

https://play.google.com/store/apps/details?id=com.asltransl

ator

MEDL Mobile Enterprises LLC

Marlee Signs

Sign ASL

Deaf Mute Helper

ASL Translator

https://apps.apple.com/us/app/marlee-
Appendix C

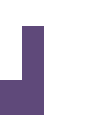

Thatching the alphabet Games

Social

communication

Teach language

No English

Text convert $\quad$ Teaching to sign program.
Social Communication
No

Android

No

Only text

Text convert

Android

No

to voice

Yes

Android

No

Text convert

to sign

Social

Communication by dictionary

Social

Communication

No

ก々

Communication

No

iOS 
Appendix D

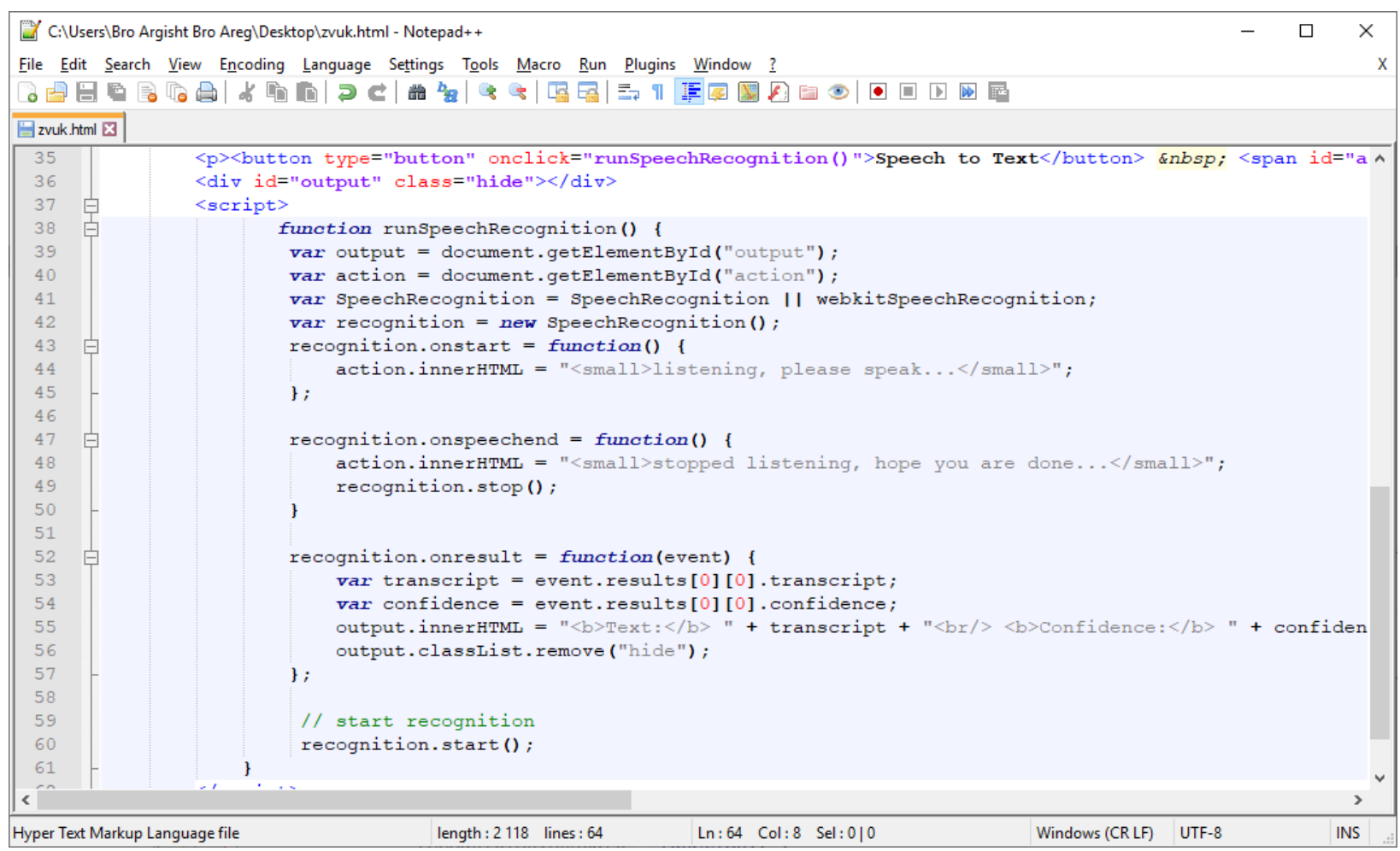




\section{Test questions}

1. How easy is the software to use?
A. Very easy
B. Easy
C. Hard
D. Very hard

2. How is the look of exterior design?
A. Very beautiful
B. Beautiful
C. Not pretty
D. Very bad

3. Was the app useful for you?

Did you learn anything?
A. Very useful
B. Useful
C. Not quit useful
D. Not useful

4. Would you advise your friends to use this app?
A. Yes absolutely
B. Yes, if they ask me
C. No, never
D. I don't know

6. Can this app help to build an inclusive school?
A. Very much
B. It can help
C. I don't know
D. Will not help

7. Can this application help in the process of building an inclusive society?
A. Very much
B. It can help
C. I don't know
D. Will not help

5. The application also has the Web version. Do you think this is good?
A. It is very good.
B. Good
C. I don't know.
D. Not necessary

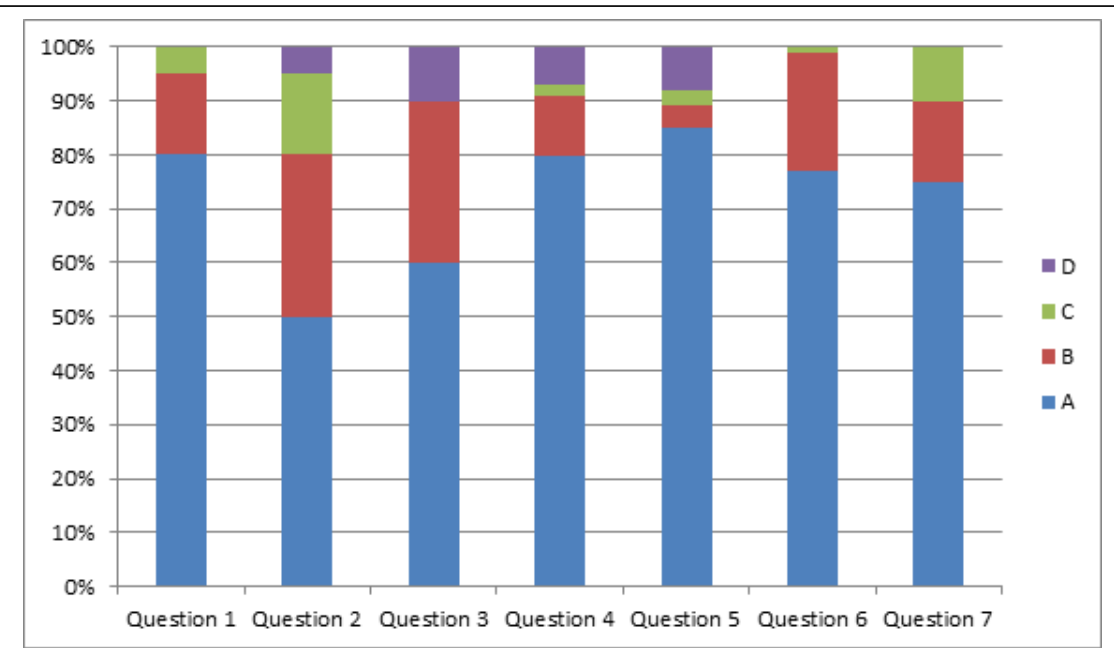




\section{Are you familiar with similar applications?}

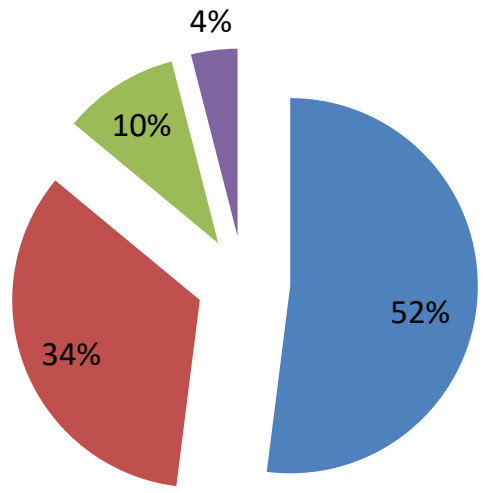

- Yes, I'm, but they have worked in foreign languages

- Yes, I'm, but they are only instructive and do not translate

- Yes, I'm and they are better than this one.

- No, I'm not

\section{Are you familiar with similar Armenian applications?}

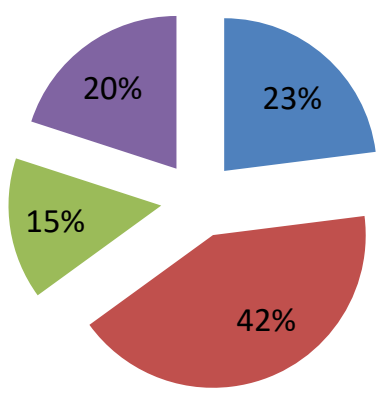

- Yes, I'm and they are better

- Yes I'm and they are the same as this one

- No, I 'm not

I have not need it 